\title{
CONFUCIANISM AND CHARACTER EDUCATION: A CHINESE VIEW
}

\author{
${ }^{1}$ Mei-Ju Chou, ${ }^{2}$ Yi-Chan Tu and ${ }^{3,4}$ Kai-Ping Huang \\ ${ }^{1}$ Department of Early Childhood Education, Taiwan Shoufu University, Taiwan \\ ${ }^{2}$ Center for Teacher Education, National Kaohsiung University of Hospitality and Tourism, Taiwan \\ ${ }^{3}$ School of Management, University of Technology, Sydney, Australia \\ ${ }^{4}$ Department of Business Administration, National Yunlin University of Science and Technology, Taiwan
}

Received 2013-04-16, Revised 2013-05-30; Accepted 2013-07-06

\begin{abstract}
The principles of Confucianism are founded on humaneness, righteousness, propriety, knowledge, integrity and filial piety. These principles have found their way to the Chinese culture since the days of Confucius. The study reviews the concept of Confucianism and its influence in Chinese context. Also, the relationship between Confucianism and character education is discussed. Character education is based on the transmission of values and within Chinese society and most of these values have been founded on the teachings of Confucius. Filial piety has strongly been conditioned within the principles of Confucianism and the respect of one's elders. Character education has been promoted by teachers and elders who focus on the transmission of values from one generation to the next. Character education is supported by the theories and teachings set out by Confucius, mostly in relation to humaneness and integrity, as well as collectivism. The individualistic trends are discarded within character education, as the welfare of the society and the collective is prioritized.
\end{abstract}

Keywords: Confucianism, Character Education, China, Chinese Society

\section{INTRODUCTION}

Confucianism is one of the oldest religions and philosophical beliefs in the world. It is a philosophical and religious system which is based on the teachings of the Chinese philosopher Confucius. Through the teachings of Confucius, the values of humaneness, righteousness, propriety, knowledge, integrity, loyalty, filial piety and continence have been described and applied (Ackerman et al., 2009; McDonald, 2012; Chunxia, 2010). In relation to education, Confucianism supports different virtues and values which are meant to highlight the importance of study in the lives of followers. This study exams confucianism and character education based on a Chinese perspective. It presents a review of literature, first covering Confucianism in the Chinese context in relation to the proposition on Confucianism being positively related to Chinese cultural contexts. It then discusses character education and character education in Chinese society. Based on the literature and argument, the following proposition will be discussed-that Confucianism is positively related to character education in Chinese society. A conclusion will then collate and summarize the study. This study is being undertaken in order to establish a more detailed and intimate understanding of Confucianism and character education.

\section{MATERIALS AND METHODS}

The study reviews the concept of Confucianism and its impact on character education in Chinese context.

\subsection{Confucianism in Chinese Context}

The main principle of Confucianism is humanism. It highlights the world and the family, not the gods or the afterlife (Fingarette, 1998; Cheng, 2011; Kim and Corresponding Author: Yi-Chan Tu, Center for Teacher Education, National Kaohsiung University of Hospitality and Tourism, Taiwan 
Strudler, 2012; Ip, 2009; Lin, 1994). Confucianism does not place much focus on faithfulness rendered to divine will (Juergensmeyer, 2005). This position is founded on the perception that humans can be taught and improved with personal and community efforts, especially selfcultivation (Zhao and Roper, 2011). It also placed much stock on virtue and ethics-ren, yi and li. Ren refers to altruism directed to other members of the community; yi seeks to support righteousness; and li refers to proper behaviour within the community (Yang, 2012). This principle also declares that one's life must be worth less than the need to uphold the values of ren and yi (Lo, 1999; Tynan et al., 2010).

Although the principles of Confucianism were abandoned for a while, the 20th century saw its revival in China. One of the principles which have been highlighted in Confucianism is filial piety (Zhang et al., 2012). This is a principle which has long been entrenched in the Chinese culture. This principle indicates that there must be deference to older individuals, mostly within one's family. This principle is perfectly encapsulated in Confucius' statement "when I walk along with two others, they may serve me as teachers. I will select their good qualities and follow them, their bad qualities and avoid them" (Grayling, 2011). Under these conditions, family is not something contrived; it is a major part of one's development. Modelling one's behaviour on one's elders is a quality seen among the Chinese; it would also explain why they would often follow their elders unquestioningly and why they seldom, if at all, question their elders and their teachers (Resick et al., 2011). Some critics of the Chinese culture also point out that the principle of filial piety often causes a lack of innovation among the Chinese, as new ideas are often suppressed and much diligence is often expressed for specific ancient literary work (Resick et al., 2011). However, despite these criticisms of these ideals, these principles fit the highly traditional culture of the Chinese.

What applies among elders seems to be apparent for the past as well. Confucianism manifests a consistency of meaning over time (Rarick, 2009). The concept of using and amending the teachings of the past matches the period and ideals of Communism. It supports sustained change, even if such change seems radical; moreover, it follows respect for new leaders, especially if the latter manifest perfect virtues.

The concept of respect for elders and for authority has been seen in various shapes and forms in China (Resick et al., 2011). Confucius has often been engaged in establishing how to gain order in society. He also supported the notion than people would live in harmony with everyone if they respected and understood the rankings of people in society (Lin, 2008). Moreover, he also expressed how social order is threatened when individuals do not recognize their specific roles in society. The culture of China influenced by Confucianism, highly reveres authority and age. In some ways, it may be regarded as egalitarian, but not in the same way as Westerners apply the concept (Pan et al., 2010). Westerners adhere to equal opportunity and standing in society, whereas the egalitarian concept for the Chinese supports equality within specific social units (Pan et al., 2010).

Although there have been changes in applications in China today, the Chinese still function based on hierarchy. Collectivism is also very much apparent in Chinese society and is very much founded on the Confucianism principles (Kelly, 2011). For smooth functioning of Chinese society, it has been important to consider the greater good of the group and the fact that individuals do not exist apart from each other (Kelly, 2011). Instead, the individual's function and relationship is based on his place in the group. In effect, the Chinese have considered the importance of suppressing their personal needs based on their collective responsibilities to the families and also their communities.

Even as some modern principles and practices have been introduced in the current Chinese culture, some traditional values have persisted (Kim and Strudler, 2012). Asian cultures are still based on modesty and humility and displaying individualism does not have a place in such culture (Kim and Strudler, 2012). In viewing the humility and modesty aspect of the Chinese culture, their ability to take compliments is notable. They are overenthusiastic about issuing compliments (He, 2011). In receiving compliments however, the Chinese are more likely to simply say 'thank you.

Part of the Confucianism teachings is based on the emphasis on the immediate and extended family. This is still very much in line with filial piety (Fangchuan, 2010). At some point, it was originally associated with devotion to parents; however, it soon extended to ancestor worship. The focus on family further supported the importance of displaying proper behaviour. In other words, an individual's success and his shame would be attributed not just to the individual, but also the entire family (He, 2011). Since Confucianism emphasizes group identity, Chinese families are usually very much involved with the lives of other members of the family. With this family first approach, the Chinese mostly assess society based on outsiders and insiders 
(Fangchuan, 2010). This is based on the concept of guanxi or connections where other people are evaluated based on the connections which can be established with them (Yeung, 2008).

Confucianism also emphasizes the importance of education and scholarship. Chinese and Asian students often work long and hard hours for their education (Fangchuan, 2010). Confucianism has placed a premium on scholarship and this element of Confucianism is still very much apparent in China, including other countries like South Korea, Taiwan and Japan. Confucianism has led to the Imperial Examination system and it is a system which has been the basis of modern civil service (Elman, 2000). Although the exam system has long been refined by other dynasties, it has been set as the main method for individuals gaining status and success in their career.

Confucius has long sought to install a system in China which is not based on aristocratic succession but meritocracy (Yang, 2012; Chunxia, 2010; Elman, 2000). Various exams imposed were very much challenging with much focus made on memorization of Confucius codes and classical literature. However, where the students were able to study and apply themselves well, they were able to secure positions as government officials, much to the pride of their families (Elman, 2000). Although such meritocracy system has been a commendable system in China, its application has sometimes been overshadowed with the guanxi practice. This practice allowed the rich and powerful members of society who had the right connections to get into good universities even if their grades did not qualify them in these schools (Yeung, 2008).

At different points of China's history, the Confucianism principles and teachings were dropped and discarded. In some ways, the ideas of Confucianism were ahead of its time. However, where opportunities for interaction with other countries soon emerged, the backward ideals of China were soon exposed (Cheng, 2011). In some ways, Confucianism was blamed for these so-called backward ideals. However, in the current context, Confucianism has gained significant favour. The focus of Confucianism on social relations seems to fit well in China's goals for social stability (Ackerman et al., 2009). A renewed interest in Confucian teachings also emerged, especially as these teachings were seen as a means of negating the entry of Western culture. Hu Jintao even supported the return to Confucian moral ethics as a means of fighting corruption (Elman, 2000). More classes in Confucianism were also offered. Thus, we propose.

\section{Proposition 1}

Confucianism is positively related to Chinese cultural contexts. More specifically, Confucianism is embedded into the Chinese culture.

\subsection{Character Education}

Character refers to the general ideals which are affected by the principles from philosophy, psychology, including sociology as well as other competing elements. Character is often utilized to how good an individual may be (Ambrose et al., 2010). The supporters of character education do not agree with what is actually good. There is also no scientific measurement of standard for it. The most common applications of character education, especially in the US are founded on school counsellors. There is however, an increased inclination to invite other professionals in its applications (Doan et al., 1991). Based on the program, the implementation process may be secured by the teachers in schools or by other adults, including other faculty members, principals, or bus drivers and even cafeteria workers.

Character education also refers to the specific effort to establish values which would be beneficial for the individual and for society in general (Yu, 2004; Ip, 2009). The virtues and values which would be learned by the citizens would likely include the values of respect, honesty, empathy and self-discipline. It would also refer to the incorporation of these values into the education curriculum (Yu, 2004). The end goal under these conditions would be to develop better values, behaviour and academic performance among students. Character education is taught to the children based on how such child is treated and how others treat other individuals in the presence of the child (Doan et al., 1991). Schools are expected to secure good character for their students and it is being managed as a significant priority for the different stakeholders in the school. It is important for schools to manifest positive character under these conditions and also to practice what they are preaching (McElmeel, 2002). Opportunities for children to display and manifest good character must also be part of their learning. Reflecting on moral issues within the curriculum is also a crucial element of character education (McElmeel, 2002). Aside from teachers, parents are significant personalities in promoting and protecting character education among students.

\subsection{Confucianism and Character Education in Chinese Society}

Eastern and Chinese philosophy and belief systems consider the inherent qualities of man as quiet and calm; 
and when the outside world intrudes, more desires emerge. As desires and wants are not adequately managed with one's consciousness being affected by the material world, there is often a loss of self and the true qualities of nature soon emerge (MacEnroe, 2001). Based on these conditions, rebellion, cunning and disobedience often comes about. This is a chaotic setup. As was already mentioned, Confucianism seeks to highlight tradition and study. It is a system which does not support those who value natural understanding or intuition (MacEnroe, 2001). Confucianism values good teachers, those who know about traditions and the practices of the ancient societies. The end-result is a reliance on the obligations and duties of the members of society (MacEnroe, 2001; Ip, 2009). Confucius also emphasizes musical training, recognizing them to be effective tools in managing the moral qualities of individuals and society.

Character education as highlighted under Confucianism emphasizes on the theory of value, with considerations on the knowledge and skills which must be learned, as well as the goals of the educational process (MacEnroe, 2001; Onsman, 2012). Confucianism has always sought to secure a reformed government, wanting to install leaders who can take on decisive roles. The theory of knowledge was also emphasized by Confucianism in relation to character education. This theory considers knowledge and its difference from belief (MacEnroe, 2001). In order to understand the ways of the world, it is important for people to observe. In observing, one must also process one's observations. In other words, beliefs would be premature if they are not adequately supported by other processes. Mistakes are often based on ill-timed knowledge founded on inadequate observations and insufficient processes (MacEnroe, 2001; Ip, 2011). Confucianism believes that lies are often founded on full knowledge and a strong misrepresentation of such information.

Morality and character is one of the most important tenets of education within the Confucianism context. Character education is based on the goals of creating individuals who are able to act with grace, speak correctly and manifest integrity in all their activities (White and Warfa, 2011; Cheung and Lee, 2010). There is a dislike for sycophantic individuals, especially men who are into clever talk and are often pretentious in their desire to secure an audience (Cheng and Low, 2010). Confucius, at some point, found himself exposed to a society where values were skewed towards what he perceived to be undesirable ends. He noted how the actions of men no longer matched the various labels which were attached to them (Cheng and Low, 2010). He also noted how the rulers did not actually rule and the subjects did not actually serve; in other words, the titles and assigned roles did not actually mean anything. Moral education has always been significant to Confucius as he considers this as a tool by which negative elements can be resolved and the values can be restored to the members of society (Starr, 2012).

Confucianism declares that teachers must not simply repeat lessons to their students, or ask their students the same questions with sustained monotony (Starr, 2012). This can be frustrating for students and ultimately would likely bore them. In the end, these students would not know the significance of learning and the benefits that their learning can bring for them. They may miss also the essential elements of education, sometimes discounting its importance and being unmotivated to pursue its ends (Cheng and Low, 2010). Teachers may also ignore the natural tendencies and interests of students and therefore, ignore what potential talents they have. As a result, these students may end up concealing their readings and sometimes disliking their teachers.

Character education in Chinese society involves much reflection. Reflection includes deep thinking and consideration of learning. Teachers must therefore reflect on what they have learned and what they would them teach. Going over what one has learned and securing a new understanding of such learning makes one worthy of being a teacher (Lin, 1994). Information can sometimes be forgotten where there is no timely revision; moreover, experience would indicate that by reflecting and rethinking events, one would learn from these experiences better (Lin, 1994; MacEnroe, 2001; Onsman, 2012). If the experience and rethinking is not taken any further, an individual would likely find himself in the same situation in the future, without any improvements on performance, facing similar failures on the incident.

Character education in Chinese society also emphasizes the importance of the teacher being aware of the common issues in the learning process (Cheng and Low, 2010). Some students may want to learn a lot and take on too many subjects; while others may seek only limited learning at a slower pace than others. Good teachers are those who seek to encourage the best out of their students, often understanding what would be good or not good for their students (Banerjee et al., 2012; Chingos and Peterson, 2011). These teachers also seek to manage the issues and difficulties encountered by their students. Some students may take longer learning and may have a different understanding or conceptualization of character education (Chingos and Peterson, 2011; 
DeWitte and Rogge, 2011). The learning process must also be based on the needs of the students. Confucianism declares that for students who understand their lessons well, the favourable results may be doubled. But for slow learners, the teaching of the values may sometimes take longer (Cheng and Low, 2010).

Teachers must therefore pitch his teaching to the students, based on their needs. In the end, students also learn from each other. In order to gain a stronger grasp of character education and values, it is important for students and also teachers to learn from each other (White and Warfa, 2011; Zhou, 2005). Learning from others means listening well to what others have to say (Brower, 2011; Zhou, 2005).

Character education is also based on one's learning while one is still young. Values and character must be transmitted the soonest possible time, with the end goal of avoiding bad habits from developing (Zhou, 2005). Bad habits therefore need to be prevented and stopped from developing any further at the soonest possible time. As bad habits become more entrenched in a person's life, it would become even more difficult to discard these practices (Cheng and Low, 2010). Moreover, similar bad habits would likely be formed if no attempts to eliminate them are taken by the teacher and by parental authorities.

Learning from negative examples and experiences is part of the process of character education within the context of Confucianism (Low, 2008; Yeh and Xu, 2010). Confucianism declares that it is the function of teachers to provide both positive and negative values and to understand how these values can both affect the individual. In understanding the negative and positive aspects of individuals, there is also a need to understand the motivations in learning (Low, 2008). Teachers need to understand the motivations of their students and as soon as that aspect is understood, the necessary adjustments in learning and character education can be made.

The role of the teachers, including parents is to teach humanistic values to the students and to the children. As was mentioned, ren is part of the principles of Confucianism and it is a concept anchored on humanity (Ting and Scisco, 2006). Confucianism advocates the importance of ren-loving other people. Under these conditions, one must have compassion. Love cannot be expressed or given to one's family alone, but it must also be expressed to the mass. Confucianism does not specify the people one is supposed to love (Cheng and Low, 2010). In the same tradition as Christianity and Buddhism, love is expected therefore to extend to all people, including one's enemy. The values of kindness and humaneness are values which have to be taught; furthermore, self-cultivation is important in providing overall learning and growth (Lin, 1994).

Confucianism also declares that in order to produce favourable results, teachers must also love their pupils (Yang, 1993). These teachers need to know their students and understand their specific qualities, as well as consider the ways by which access to knowledge can be secured. The transmission of values comes from the teacher's and the parent's heart and passion (Cheng and Low, 2010). Confucianism also supports the importance of teachers finding joy in their students and in their teaching. Loving students in other words is also equivalent to being committed in their student's development (Low, 2010). As the teacher transmits love, he would also be more patient and caring towards the student. In turn, the student would likely learn to embrace his learning.

In upholding character and integrity to a premium, teachers also need to consider the moral development of their students. This would involve the process of teaching students about life and good living. Most people should therefore uphold virtue and as virtue is prioritized, good conscience is also enjoyed (Low, 2008). Moral education, as pointed out by Confucius, is important because it is the means by which a person can manage negative and unfavourable actions and behaviours, highlighting values and character as significant aspects of learning.

Confucianism is based on the traditional values and practices of Confucius. His teachings and values are based on ethics and statecraft which created for China a society dominated by the elite (Starr, 2012). The elite under these conditions are taken from the merit-based examination system established under the Confucianism principles. Education has been considered the means by which social status and material success can be gained. Education has also long promoted morality and the relevance of hierarchy. The place of education ranks high in the culture secured by Confucian values (Chandler and Richardson, 2008). This is supported by the extent of parental interests attributed to children, mostly in pressuring these children to succeed in their studies. Their education is even considered a major and priority expense in the financial expense of the family. The learning process is therefore as important as the information transmitted to the learners (Boneau, 2012). In character learning, the role of the family and authority figures is rated high in the list of priorities.

Confucianism supports the relevance of education and cultivation of the individual and humanity is something which needs to be instructed and transmitted 
to the members of society. Gaining humanity is a major achievement for most people and with the application of personal refinement and self-articulation, it possible to promote propriety (Yeh and $\mathrm{Xu}, 2010$; Lin, 1994). Propriety is based on social roles which protect the rites of life and death. These elemental structures are based on the behaviour of society which is also supported by the quality person. Such person is shaped through character education, mostly on encouraging proper conduct and ensuring more selfless behaviour (Lin, 1994). The premise in character education is that one's social self is a major obstacle to self-realization.

Excellence or virtue which is gained by the members of the community can also empower the society to be models of propriety for the generations which would follow them (Starr, 2012). The power of the community is self-regulating and is founded on the efficacy of authoritative leaders, not so much on the application of external elements like laws and punishment (Starr, 2012). It is important to note that the relevance of strong models of propriety in Confucian society clashes with the emphasis made on the ethical elements which are often seen among rationalized communities. In China and some other Confucian societies, there are various individuals like Confucius himself and Kings Yao and Shun who are considered self-realized individuals (Starr, 2012). They are models of emulation. Character education often features their behaviour and actions as models and standards of behaviour. Propriety is paramount to the character education in Chinese society. Propriety usually supports proper conduct in one's relations with family and with society. It also eventually supports the traditional and appropriate norms which can be made one's own (Cheng and Low, 2010). The concept of rightness within Confucian society as it is applicable to a social context also includes the concepts of harmony. Proper actions are appropriate and are fitting as far as they also fit in with other similar actions.

The concept of right action and behaviour has a lot in common with the individual's right choice, choices which usually colour and impact on their personal growth (Lin, 1994). Failing to engage in character education within the Confucian society is often based on the entry of Western practices. Confucian values have often been viewed by Western societies as archaic and they believe that it is more than a hindrance to their societal development. Character education within Confucian society has been protected by the ancient rituals and perception its people, including the deeply entrenched values of filial piety, compassion and humaneness (Starr, 2012). Thus, we propose.

\section{Proposition 2}

Confucianism is positively related to character education in Chinese society. More specifically, character education is essential in Chinese society and Confucianism has established values and appropriate behaviour expected from the members of society.

\section{CONCLUSION}

Confucianism is founded on the teachings of Confucius, a philosopher who has long advocated and specified the elements of humaneness as well as other proper behaviour as crucial values in society. Education has also been considered as a tool by which the teachings of Confucius have been promoted. Character education has provided the means by which the values and teachings of Confucius has been transmitted to the people. Within Chinese society, the teachings and expectations of filial piety have long been deeplyentrenched. Character education based on Confucian principles is based on the teachings of parents and of teachers. The transition of these values from one generation to the next is founded on the older generations which are considered role models who are expected to teach the younger generations the specific and appropriate values of Confucianism.

\section{REFERENCES}

Ackerman, D., J. Hu and L. Wei, 2009. Confucius, cars and big government: Impact of government involvement in business on consumer perceptions under confucianism. J. Bus. Ethics, 88: 473-482. DOI: 10.1007/s10551-009-0304-9

Ambrose, S.A., M.W. Bridges, M. DiPietro, M.C. Lovett and M.K. Norman et al., 2010. How Learning Works: Seven Research-Based Principles for Smart Teaching. 1st Edn., Jossey-Bass, USA., ISBN-10: 0470484101, pp: 336.

Banerjee, R., E.M. King, P.F. Orazem and E.M. Paterno, 2012. Student and teacher attendance: The role of shared goods in reducing absenteeism. Econ. Educ. Rev., 31: 563-574.

Boneau, C., 2012. Hermann Ebbinghaus: On the Road to Progress or Down the Garden Path. In: Portraits of Pioneers in Psychology, Kimble, G.A., C.A. Boneau and M. Wertheimer (Eds.), Psychology Press, Mahwah, NJ., ISBN-10: 1135691053, pp: 51-64.

Brower, H.H., 2011. Sustainable development through service learning: A pedagogical framework and case example in a third world context. Acad. Manage. Learn. Educ., 10: 58-76. 
Chandler, S. and S. Richardson, 2008. 100 Ways to Motivate Others: How Great Leaders Can Produce Insane Results Without Driving People Crazy. 1st Edn., Career Press, ISBN-10: 1564149927, pp: 240.

Cheng, C., 2011. Confucian global leadership in Chinese tradition: classical and contemporary. J. Manage. Dev., $\quad 30$ : 647-662. $10.1108 / 02621711111150173$

Cheng, K. and P. Low, 2010. Teaching and education: The ways of confucius. Educ. Res., 1: 681-686.

Cheung, C. and T. Lee, 2010. Improving social competence through character education. Eval. Program Plann., 33: 255-263. DOI: 10.1016/j.evalprogplan.2009.08.006

Chingos, M.M. and P.E. Peterson, 2011. It's easier to pick a good teacher than to train one: Familiar and new results on the correlates of teacher effectiveness. Econ. Educ. Rev., 30: 449-465. DOI: 10.1016/j.econedurev.2010.12.010

Chunxia, W., 2010. The influence of Confucian culture on business management: A case study of Chinese entrepreneurs in Macau. Int. J. Bus. Anthropol., 1: 117-134.

DeWitte, K. and N. Rogge, 2011. Accounting for exogenous influences in performance evaluations of teachers. Econ. Educ. Rev., 30: 641-653. DOI: 10.1016/j.econedurev.2011.02.002

Doan, T.V., V. Shen, G.F. McLean, V.D. Tran and Q. Shen, 1991. Chinese Foundations for Moral Education and Character Development. 1st Edn., Council for Research in Values, Beijing, ISBN-10: 156518033X, pp: 200.

Elman, B.A., 2000. A Cultural History of Civil Examinations in Late Imperial China. 1st Edn., University of California Press, USA., ISBN-10: 0520215092, pp: 889.

Fangchuan, H., 2010. The construction of East Asian culture and cultural awareness. Proc. Soc. Behav. Sci., 2: 7198-7202. DOI: 10.1016/j.sbspro.2010.05.075

Fingarette, H., 1998. Confucius: The Secular as Sacred. 1st Edn., Waveland Press, ISBN-10: 1577660102, pp: 84.

Grayling, A.C., 2011. The Good Book: A Secular Bible. 1st Edn., Bloomsbury Publishing, London, ISBN10: 0747599602, pp: 608.

He, N., 2011. Case study on the influence of Chinese traditional philosophy to the enterprise management. J. Manage. Strategy, 2: 73-78. DOI: 10.5430/jms.v2n3p73
Ip, P.K., 2009. Is confucianism good for business ethics in China? J. Bus. Ethics, 88: 463-476. DOI: 10.1007/s10551-009-0120-2

Ip, P.K., 2011. Practical wisdom of confucian ethical leadership: A critical inquiry. J. Manage. Dev., 30: 685-696. DOI: 10.1108/02621711111150209

Juergensmeyer, S.B.M., 2005. Religion in Global Civil Society. 1st Edn., Oxford University Press, Oxford, ISBN-10: 0198040695, pp: 240.

Kelly, R.E., 2011. A confucian long peace' in preWestern East Asia. Eur. J. Int. Relat., 18: 407-430. DOI: $10.1177 / 1354066111409771$

Kim, T.W. and A. Strudler, 2012. Workplace civility: A confucian approach. Bus. Ethics Q., 22: 557-577. DOI: $10.5840 /$ beq 201222334

Lin, C., 2008. Demystifying the chameleonic nature of Chinese leadership. J. Leadership Organ. Stud.,, 14: 303-321. DOI: $10.1177 / 1548051808315552$

Lin, Y., 1994. The Wisdom of Confucius. 1st Edn., The Modern Library, London.

Lo, P.C., 1999. Confucian ethic of death with dignity and its contemporary relevance. Ann. Soc. Christ. Ethics, 19: 313-333. PMID: 11913447

Low, K.C.P., 2008. Value-based leadership: Leading, the confucian way. Leadership Organ. Manage. J., 3: 32-41.

Low, K.C.P., 2010. Applying soft power, the confucian way. Conflict Resolut. Negotiat. J., 4: 37-46.

MacEnroe, A.M., 2001. Confucius's educational theory.

McDonald, P., 2012. Confucian foundations to leadership: A study of Chinese business leaders across Greater China and South-East Asia. Asia Pacific Bus. Rev., 18: 465-487. DOI: 10.1080/13602381.2012.693770

McElmeel, S.L., 2002. Character Education: A Book Guide for Teachers, Librarians and Parents. 1st Edn., Libraries Unlimited, London, ISBN-10: 1563088843, pp: 228.

Onsman, A., 2012. Recognising the ordinances of heaven: The role of Confucianism in higher education management in the People's Republic of China. J. Higher Educ. Policy Manage., 34: 169184. DOI: 10.1080/1360080X.2012.662741

Pan, Y., X. Song, A. Goldschmidt and W. French, 2010. A cross-cultural investigation of work values among young executives in China and the USA. Cross Cultural Manage.: Int. J., 17: 283-298. DOI: $10.1108 / 13527601011068379$

Rarick, C.A., 2009. The historical roots of Chinese cultural values and managerial practices. J. Int. Bus. Res., 8: 59-68. 
Resick, C.J., G.S. Martin, M.A. Keating, M.W. Dickson and H.K. Kwan et al., 2011. What ethical leadership means to me: Asian, American and European perspectives. J. Bus. Ethics, 101: 435-457. DOI: 10.1007/s10551-010-0730-8

Starr, D., 2012. A position paper commissioned and published by Universitas 21, the leading global network of research universities for the 21 st century. Routledge, Singapore.

Ting, S. and P. Scisco, 2006. The CCL Handbook of Coaching: A Guide for the Leader Coach. 1st Edn., Jossey-Bass, London, ISBN-10: 0787976849, pp: 496.

Tynan, C., M.T.P. Heath, C. Ennew, F. Wang and L. Sun, 2010. Self-gift giving in China and the UK: Collectivist versus individualist orientations. J. Market. Manage., 26: 1112-1128. DOI: 10.1080/0267257X.2010.508981

White, R. and N. Warfa, 2011. Building schools of character: A Case-study investigation of character education's impact on school climate, pupil behavior and curriculum delivery. J. Applied Social Psychol., 41: 45-60. DOI: 10.1111/j.1559-1816.2010.00701.x

Yang, B., 2012. Confucianism, socialism and capitalism: A comparison of cultural ideologies and implied managerial philosophies and practices in the P. R. China. Hum. Resou. Manage. Rev., 22: 165-178. DOI: 10.1016/j.hrmr.2012.01.002
Yang, H., 1993. Confucius (Kung Tzu) 551-479 BC. Prospects: The Quarterly review of comparative education. UNESCO: Int. Bureau Educ., 13: 211219.

Yeh, Q.J. and X. Xu, 2010. The effect of confucian work ethics on learning about science and technology knowledge and morality. J. Bus. Ethics. 95: 111128. DOI: $10.1007 / \mathrm{s} 10551-009-0352-1$

Yeung, H.W.C., 2008. Handbook of research on Asian business. 1st Edn., Edward Elgar Publishing, London, ISBN-10: 1848440928, pp: 512.

$\mathrm{Yu}, \mathrm{T}$., 2004. In the Name of Morality: Character Education and Political Control. 1st Edn., Peter Lang, London, ISBN-10: 0820467251, pp: 168.

Zhang, S., W. Liu and X. Liu, 2012. Investigating the relationship between protestant work ethic and Confucian dynamism: An empirical test in Mainland China. J. Bus. Ethics, 106: 243-252. DOI: 10.1007/s10551-011-0993-8

Zhao, L. and J. Roper, 2011. A Confucian approach to well-being and social capital development. J. Manage. Dev., 30: 740-752. DOI: 10.1108/02621711111150245

Zhou, K., 2005. A Basic Confucius: An Introduction To The Wisdom And Advice Of China's Greatest Sage. 1st Edn., Long River Press, London, ISBN-10: 1592650406, pp: 198. 